\title{
A CIDADE EM DIÁLOGO COM A SUSTENTABILIDADE
}

\author{
Aline Calazans Marques ${ }^{1}$ \\ Leopoldo Eurico Gonçalves Bastos ${ }^{2}$ \\ Frédéric Bonneaud ${ }^{3}$
}

\begin{abstract}
RESUMO
O artigo trata da associação entre a cidade e a sustentabilidade contemporânea, adotando a percepção urbana como mediadora do discurso. A reflexão proposta foi motivada pelo interesse no discurso fenomenológico da percepção do espaço urbano na atualidade. O objetivo do artigo é apresentar a construção de um diálogo entre a sustentabilidade e a cidade, destacando o pensar sustentável como um agente motivador de intervenções urbanas. A metodologia adotada envolveu duas principais linhas de ação. Inicialmente, incluiu a pesquisa bibliográfica referente aos princípios da sustentabilidade no contexto contemporâneo, urbanismo sustentável e a percepção da cidade. Em seguida, concentrou-se na investigação de intervenções urbanas comprometidas com as premissas da sustentabilidade e a análise destas intervenções sob a ótica da percepção. Compreende-se, portanto, que a constante reformulação do sentido da sustentabilidade colabora para o debate sobre a cidade em diferentes escalas e setores. Aproxima o olhar do homem à sua própria integração no espaço urbano, reduzindo a distância entre dois elementos que precisam se reconhecer cada vez mais integrados e co-responsáveis: o homem e a cidade.
\end{abstract}

PALAVRAS-CHAVE: Cidade, Sustentabilidade, Percepção urbana.

\section{THE CITY IN DIALOGUE WITH SUSTAINABILITY}

\author{
ABSTRACT \\ The article addresses the association between the city and contemporary sustainability, adopting the \\ urban perception as mediator of the discourse. The proposed thinking was motivated by the interest in

\footnotetext{
${ }^{1}$ Mestre em Engenharia Civil. Doutoranda em Arquitetura do Programa de Pós-Graduação em Arquitetura da Universidade Federal do Rio de Janeiro, PROARQ-FAU/UFRJ em cotutela com o Institut National des Sciences Appliquées - INSAT, LRA - Laboratoire de Recherche em Architecture, Toulouse / France. alinemarques@pucminas.cesjf.br

${ }^{2}$ Doutor em Engenharia Mecânica, Professor do Programa de Pós-Graduação em Arquitetura da Universidade Federal do Rio de Janeiro- PROARQ-FAU/UFRJ. leopoldobastos@gmail.com

${ }^{3}$ Arquiteto, Doutor. Professor da Ecole Nationale Supérieure d'Architecture - ENSAT, LRA Laboratoire de Recherche en Architecture, Toulouse/France. frederic.bonneaud@toulouse.archi.fr
} 


\section{Revista Nacional de}

Gerenciamento de Cidades

dos materiais e tecnologias à escala da cidade ou do fragmento urbano, dentro de uma abordagem ecossistêmica.

O artigo tem como objetivo apresentar a construção de um diálogo entre a sustentabilidade e a cidade, destacando o pensar sustentável como um agente motivador de intervenções urbanas.

Como objetivos específicos relacionam-se:

- Identificar propostas que incentivem a adoção de princípios de sustentabilidade na cidade;

- Promover o debate sobre a cidade e seu habitante, com vistas a incentivar o desenvolvimento sustentável;

- Incentivar a compreensão da cidade sob novas perspectivas;

- Incentivar o debate entre arquitetos e urbanistas, diferentes atores sociais e o poder público.

O procedimento metodológico adotado para este estudo, teve como ponto de partida, a pesquisa bibliográfica dedicada a três temas: os princípios da sustentabilidade no contexto contemporâneo, o urbanismo sustentável e a percepção da cidade. Em seguida, concentrou-se na investigação de intervenções urbanas comprometidas com as premissas da sustentabilidade e a análise destas intervenções sob a ótica da percepção. Dentre os principais autores adotados como referência para a construção do discurso, podemos citar: Acselrad (2001); Chauí (2000); Gehl (2010); Panerai (2006); Panerai, Castex e Depaule (1997); Perulli (2012); Wachter (2010) e, Younès e Bonnaud (2014).

Em síntese, o texto apresenta a cidade a partir da relação com o habitante, a partir da escala, do olhar, da ação e da interação do espaço com seu próprio usuário. Para tanto, a percepção do espaço urbano, é adotada como contraponto teórico e orientadora do discurso.

O resultado é exposto neste artigo como instrumento de reflexão. Reconhecer o potencial dos requisitos da sustentabilidade não apenas como meta, mas como elemento mobilizador do debate e da ação, incentiva intervenções 
Revista Nacional de

Gerenciamento de Cidades

pontuais e imediatas, que devem se manter comprometidas com os possíveis desdobramentos futuros. $\mathrm{O}$ amadurecimento do sentido da sustentabilidade e sua aplicabilidade diversificada incentiva o surgimento de novas perspecitvas e maneiras de compreender e intervir sobre o objeto, em suas diferentes escalas. Aproxima o olhar do homem à sua própria integração com a cidade, reduzindo a distância entre os dois elementos que precisam se reconhecer cada vez mais integrados e coresponsáveis, o homem e a cidade.

O texto está estruturado em três etapas. O tópico inicial, trata do sentido da sustentabilidade no contexto contemporâneo. Em seguida, apresenta-se a associação entre a sustentabilidade e a cidade. O terceiro tópico, se concentra na prática da percepção urbana e sua relação com o sentido de cidade sustentável. Pretende, portanto, através da reflexão apresentada neste artigo, colaborar para o debate proposto pela temática do evento.

\section{REFLEXÕES SOBRE A SUSTENTABILIDADE CONTEMPORÂNEA}

Desde o início dos anos 90, o termo "sustentabilidade" vem sendo incorporado a diferentes áreas do saber. A publicação do relatório Bruntland (1991), tornou-se referência para a construção do sentido de sustentabilidade, que se baseia na dialética entre três polos: as demandas econômicas, a integridade ecológica e a equidade social.

No âmbito da arquitetura e do urbanismo, de acordo com Acselrad (p.36, 2001), "a associação da noção de sustentabilidade com o debate sobre desenvolvimento das cidades tem origem nas rearticulações políticas (...)". Nesse sentido, o Protocolo de Kyoto em 1997 e Agenda 21, resultante da Conferência da ONU sobre Desenvolvimento e Meio Ambiente são eventos que motivaram reflexões entre a sustentabilidade e a produção do espaço urbano. A partir de então, a diversidade de definições acerca do termo sustentabilidade e sua constante reformulação enriquece a discussão sobre 0 tema $e$ seus possíveis 


\section{Revista Nacional de}

Gerenciamento de Cidades

desdobramentos.

O sentido da sustentabilidade na contemporaneidade assume diferentes dimensões de acordo com cada área do conhecimento a que se aplica. Apesar de reconhecer esta diversidade, entende-se que a crítica elaborada por Seghezzo (2009), se enquadra de maneira pertinente à discussão proposta por este artigo. Seghezzo (2009), propõe uma releitura das três dimensões básicas da sustentabilidade (econômico, social e ambiental), a partir da relação entre os conceitos de Place, Permanence e Persons. Sendo, o "lugar" e o "indivíduo" (representam a dimensão humana), como a base, representando o real, as coisas concretas que existem num determinado tempo. A "permanência" é o conector do triângulo, representa o ideal, abstrato, subjetivo, inerente à noção de evento. Podese então, a partir destes três novos "Ps", reconhecer as cinco dimensões propostas por Seghezzo (2009), como uma proposta mais abrangente e integrada do sentido de sustentabilidade. "Place": contém as três dimensões do espaço $(x, y, z)$, "Permanence" inclui a dimensão do tempo e "Persons", a dimensão humana.

Portanto, o sentido de sustentabilidade inclui cada vez mais o homem como agente e não apenas como beneficiário. Não como aquele responsável pelos prejuízos ao ambiente contabilizados até agora, mas como aquele responsável pelas ações de hoje e de amanhã que podem trazer benefícios ao meio em que habita. $O$ indivíduo deve então, desempenhar um papel crítico e proativo, ético e responsável mediante os desafios de seu tempo.

\section{CIDADE E SUSTENTABILIDADE}

Agir de acordo com as premissas da sustentabilidade, implica dedicação a um complexo conjunto de ações amplamente discutidas e experimentadas por diferentes setores. É necessário reconhecer a complexidade da cidade, com uma rede de bairros, seus volumes e vazios integrados por vias, eixos e conexões. Para Perulli (p.15, 2012), a cidade é, "um sistema de organização conectado em rede, em 


\section{Revista Nacional de}

Gerenciamento de Cidades

que cada parte influencia o conjunto, ou melhor, um sistema de organização dinâmica em rede que se modifica no espaço e no tempo".

Na visão de Pezzi (p. 59, 2007) muitas decisões urbanísticas têm causado efeitos duradouros sobre a sociedade e a qualidade de vida dos habitantes assim como sobre o meio ambiente. Na escala urbana, investir esforços em ações que visem a economia de combustíveis fósseis e o uso adequado de recursos energéticos, são cada vez mais urgentes. Mas o autor destaca que a eficiência energética não é um objetivo em si, sendo apenas parte de uma busca integrada pelo desenvolvimento sustentável.

Compreender a cidade como um ecossistema, segundo Acselrad (p.38-42, 2001) é uma das matrizes de representação da cidade, que incentiva a diminuição do consumo e a reutilização dos resíduos criando um ciclo contínuo e mais equilibrado, entendendo a cidade como um organismo. Este raciocínio se aplica a diferentes escalas na arquitetura. Podemos considerar o indivíduo, a habitação, o edifício, o quarteirão, o bairro, a cidade, a região; enfim, a ideia de uma área urbana que precisa importar seus insumos e depois de consumidos precisa exportar seus dejetos, deve ser questionada.

Para Panerai, (1997, p.178) a questão do tecido urbano não pode estar dissociada da experiência cotidiana e da cidade. Construir a cidade hoje, não se limita a funcionalidade, pode significar uma vontade de lidar com as formas entre suas diferentes qualidades: a proximidade, a mistura e o imprevisto. Ressalta ainda, a importância de ações sustentáveis no projeto urbano como um espaço público acessível a todos, vizinhanças mistas, atividades que se misturam, edifícios que se adaptem e se transformem.

Portanto, em consonância com o exposto por Acselrad (p.37, 2001), acredita-se que a questão ambiental esteja imersa no debate sobre políticas urbanas, assim como as questões urbanas encontram espaço no debate ambiental. Ao pensar o espaço urbano a partir das premissas sustentáveis, os laços entre os projetistas e o setor público, parecem se estreitar através das políticas urbanas. 


\section{A PERCEPÇÃO DO ESPAÇO URBANO}

As teorias que abordam a temática da "percepção", encontram na filosofia e na psicologia espaço para seu desenvolvimento. Segundo Chauí (p.155-156, 2000), o entendimento do sentido de percepção deve ser construído a partir de três diferentes teorias do conhecimento: a empirista, a intelectualista e a fenomenológica. Para a teoria empirista, "a percepção é a única fonte de conhecimento, estando na origem das ideias abstratas formuladas pelo pensamento". Para a intelectualista, "a percepção é considerada não muito confiável para o conhecimento porque depende das condições particulares de quem percebe e está propensa a ilusões (...)”. Já na teoria fenomenológica, "a percepção é considerada originária e parte principal do conhecimento humano (...)".

A partir da ótica de Chauí (p.154, 2000), diferente das teorias empirista e intelectualista, a percepção tem, portanto, dentre outras características, a compreensão de que o "mundo percebido é qualitativo, significativo, estruturado e estamos nele como sujeitos ativos, isto é, damos às coisas percebidas novos sentidos e novos valores (...)". A relação que se estabelece entre o sujeito e o mundo que o envolve, segundo Chauí (p.154, 2000), "dá sentido ao percebido e ao percebedor, e um não existe sem o outro". A maneira pela qual o homem se apropria dos espaços, é o que lhe dá sentido, significado.

Ao tratar de percepção e sensação, Younès e Bonnaud (2014) observa no espaço arquitetônico, um grande número de dimensões sensoriais a serem experimentadas pelo homem e, que através do homem, ganha uma multiplicidade de significados. "A luz e a sombra, as transparências, os materiais e as texturas, as relações de escala, o tamanho de nossos corpos, (...) são alguns dos elementos que participam de maneira simultânea da descoberta e da apreensão de um lugar". YOUNÈS; BONNAUD (p.125, 2014)

Em consonância com as premissas da sustentabilidade, faz-se necessário 


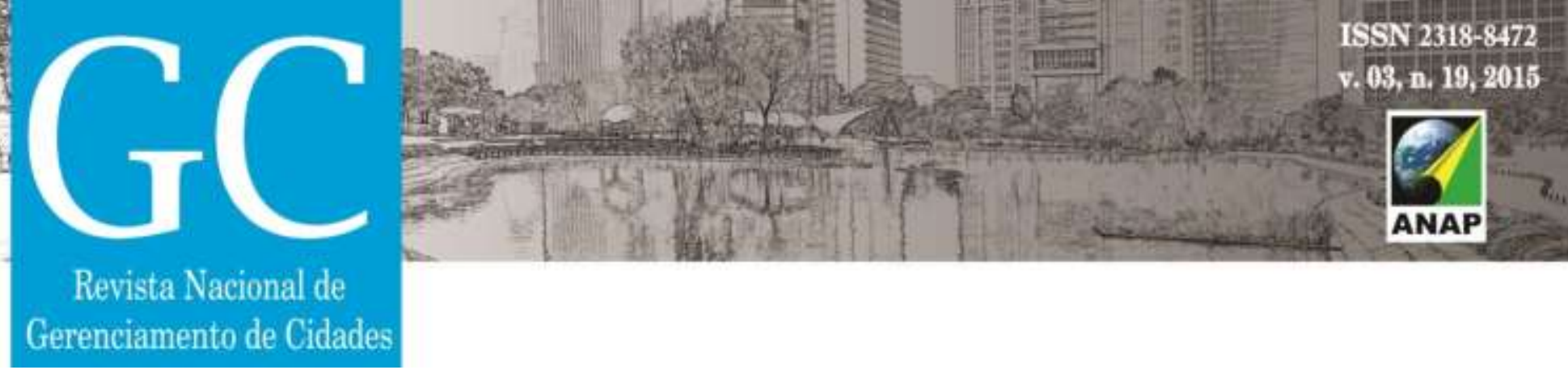

repensar os espaços e experimentar novas configurações do mesmo. A Figura 1 apresenta a placa indicativa de prioridade fixada em uma área de uso compartilhado no centro da cidade de Bordeaux na França. A placa traz para esta reflexão, a ordem de prioridade através da escala das figuras do homem, da bicicleta e do veículo motorizado. Indica ainda, o limite de velocidade, colaborando para a identidade de um espaço que prioriza o pedestre e incentiva o deslocamento em um ritmo lento, que favorece a percepção do espaço urbano.

Figura 1: Placa indicativa de prioridade na área de uso compartilhado em Bordeaux - França

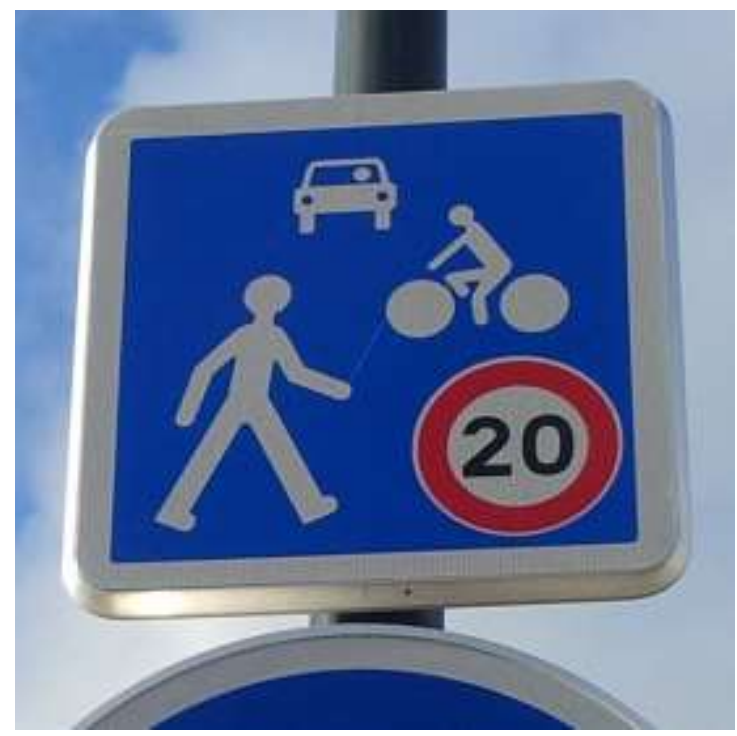

Fonte: ACERVO PESSOAL, 2014.

O espaço de uso compartilhado tornou-se uma iniciativa frequente nas cidades europeias que investiram em restruturação urbana. O deslocamento do fluxo intenso de veículos para as periferias é uma das alternativas demonstradas por Gehl (2010), que viabilizam a criação de espaços livres, geralmente em áreas turísticas, nos centros urbanos antes saturados. A rua, como espaço público se amplia, criando oportunidades de convivência entre pedestre, bicicletas, veículos lentos, não se limitando a ser apenas um eixo de deslocamento. Alterando a percepção do sujeito 
Revista Nacional de

Gerenciamento de Cidades

em relação ao espaço onde novos significados podem surgir.

Younès e Bonnaud (p. 180, 2014) através de uma metáfora, em referência a Humberto Eco, compara o espaço ao texto escrito, que aguarda seu leitor. "O espaço aguarda o promeneur (o transeunte), que o descobre ao longo do tempo e o compreende mentalmente, fisicamente, de acordo com o seu caminho, na sucessão de suas descobertas e de sua competência".

Em contraponto ao caminhar, ou seja, à percepção do espaço através do corpo inteiro, Pallasmaa (2005) assim como Younès e Bonnaud (p.125-126, 2014), apontam na cultura ocidental, a preponderância da visão sobre os demais sentidos, o que pode comprometer ou restringir a percepção na sua completude. Uma das maneiras mais recentes de compreensão do espaço pelo canal visual é através das ferramentas digitais. Os mapas digitais da Google, GPS (sistema de posicionamento global), os softwares tridimensionais (ferramenta de representação e concepção de arquitetos e urbanistas) e a realidade virtual, são alguns exemplos que remetem às telas e câmeras citadas por Younès e Bonnaud (p.126, 2014).

Ao mesmo tempo em que criam novas dinâmicas de percepção do espaço, substituem o movimento do corpo (que interagia com o espaço físico) pelo movimento dos olhos e toques que interagem com o espaço virtual através da tela. O percurso, por vezes, perde importância, enquanto o ponto de chegada se torna o principal objetivo. A leitura da cidade por ferramentas digitais é objeto do discurso de Wachter (2010), onde o surgimento de novas maneiras de vivenciar e interagir com a cidade gera, ao mesmo tempo, riscos e potencialidades para o desenvolvimento sustentável urbano.

\section{CONCLUSÕES E DESDOBRAMENTOS}

A reflexão proposta por este artigo pretendeu elaborar um diálogo entre a cidade e a sustentabilidade, utilizando da percepção urbana como interlocutora do discurso. Ao longo desta construção teórica, pode-se identificar algumas conclusões 


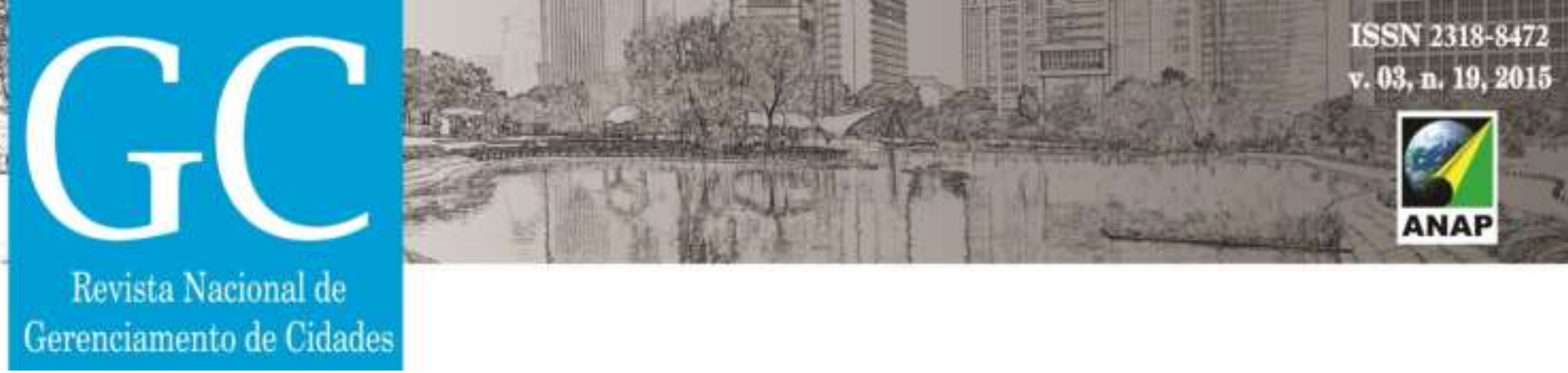

parciais que colaboram para a construção de novas questões.

A conclusão não propõe o encerramento do assunto em si mesmo, mas identifica alguns pontos que merecem atenção. Um deles, é a compreensão das premissas da sustentabilidade não apenas como meta, mas como ponto de partida para o desenvolvimento de novas iniciativas. Quando esta lógica se aplica ao exercício de pensar a cidade, cria oportunidades e novas perspectivas. Outro ponto relevante, é o debate resultante das incertezas acerca da sustentabilidade. O que a princípio, pode parecer uma fragilidade, é justamente o que movimenta a discussão e incentiva o esforço por alternativas mais eficientes.

O sujeito "percebedor" proposto por Chauí (p.154, 2000) é o mesmo que para os pressupostos da sustentabilidade deve se apresentar cada vez mais como agente e não apenas como beneficiário. Compreender a percepção como uma estratégia de interpretação e apreensão do espaço urbano, incentiva o diálogo entre a cidade e seu habitante, e por fim, favorece o desenvolvimento urbano sustentável.

Os possíveis desdobramentos vislumbrados, encontram diferentes perspectivas nas áreas acadêmica e profissional. Onde entende-se que, arquitetos e urbanistas devem atuar de maneira colaborativa e integrada às esferas sociais e políticas, a fim de alcançar alternativas favoráveis ao desenvolvimento urbano de acordo com as premissas da sustentabilidade.

\section{AGRADECIMENTOS}

Os autores agradecem à CAPES-COFECB, pelo auxilio através da bolsa de estudos do projeto ${ }^{\circ} 693 / 10$, cooperação entre Brasil e França.

\section{REFERÊNCIAS}

ACSELRAD, Henri (org.). A duração das cidades: sustentabilidade e risco nas políticas urbanas. Rio de Janeiro: DP\&A, 2001. 240p. 


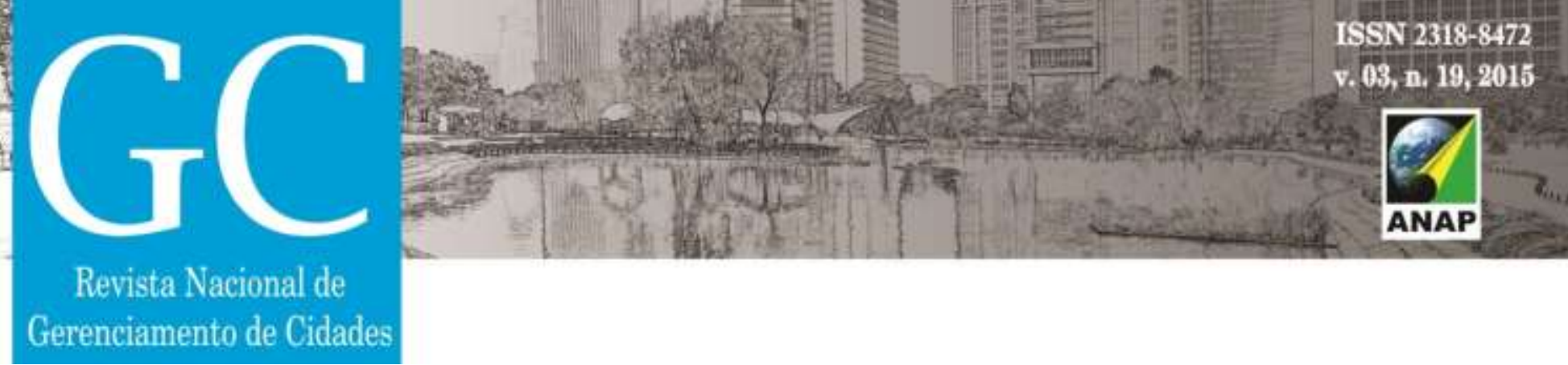

BRUNTLAND, G.H. Nosso Futuro Comum. 2ª Ed. Rio de Janeiro: FGV, 1991.

CHAUÍ, M. Convite à filosofia. 12ª Ed. São Paulo: Editora Ática, 2000. 567p.

FERNANDEZ, Pierre; LAVIGNE, Pierre. Concevoir des bâtiments bioclimatiques fondements \& méthodes. Paris: Éd. le Moniteur, 2009. 430p.

GEHL, Jan. Cities for People. Washington, DC: Island Press, 2010.

PALLASMAA, Juhani. The eyes of the skin: architecture and the senses. Chichester; Hoboken, NJ: Wiley-Academy; John Wiley \& Sons, 2005.

PANERAI, Philippe; CASTEX, Jean; DEPAULE, Jean-Charles. Formes Urbaines - de l'îlot à la barre. Marseille: Parenthèses, 1997. 196p.

PERULLI, Paolo. Visões da Cidade. As Formas do Mundo Espacial. São Paulo: Ed. Senac SP, 2012. 254p.

PEZZI, Carlos Hernández. Um Vitruvio Ecológico: Princípios y Práctica del Proyecto Arquitectónico Sostentable. Barcelona: GG, 2007. 159p.

SEGHEZZO, Lucas. The five dimensions of sustainability. Environmental Politics, v.18 - n.4, 539556, 2009.

WACHTER, Serge. La ville interactive. L'architecture et l'urbanisme au risque du numérique et de l'écologie. Paris: L'Harmattan, 2010. 236p.

YOUNĖS, Chris; BONNAUD, Xavier. Perception, architecture, urbain. Clermont Ferrand: Infolio, 2014. 347p. 